Methods A prospective observational study was performed using a repeated measures design in children from 3-17 years in two intensive care and high-dependency units in Ireland. Interrater reliability was tested among nurses using linearly weighted kappa, Cronbach $\alpha$ was applied to test internal consistency of the COMFORT-B scale and concurrent validity involved comparing COMFORT-B with the FLACC and Numeric Rating Scale score of nurses.

69 paired nursing assessments to test the interrater-reliability of the COMFORT-B scale was performed. With a high interrater-reliability of Cronbach 0.87 , Single nurse observations were commenced of the COMFORT-B, NRS and FLACC/Selfreport scores at specific four-hourly intervals over the first $48 \mathrm{~h}$ of each admission.

Results Data in 19 patients (age 3 to 17 years) was collected for the pilot study. Initial compliance of $4 \%$ increased to over $80 \%$. Interrater reliability between COMFORT, FLACC and NRS remained high throughout the study.

Conclusion The COMFORT-B is suitable for use in children and adolescents from 3-17years.

\section{P0-0867 WITHDRAWN}

\section{Nursing - Neonatal Brain and Development}

PO-0868 NEUROMONITORING; HOW TO TRAIN YOUR NURSING
STAFF

J Zoet-Lavooi, LGM van Rooij, AJ Brouwer, P Lemmers, LS de Vries. Neonatology, Wilhelmina Children's Hospital University Medical Center Utrecht, Utrecht, Netherlands

\subsection{6/archdischild-2014-307384.1492}

Background and aims Neuromonitoring, using amplitude-integrated Electroencephalography (aEEG) and near infra-red spectroscopy (NIRS), is common practice on our Neonatal Intensive Care Unit (NICU). The quality of the registration depends on the application of the aEEG-needles or hydrogel electrodes and the NIRS-pad, handling the equipment and interpretation of the registration.

Incorrect placement of the electrodes (too close to each other) by untrained nursing staff can lead to a registration full of artefacts, which may be interpreted as epileptic events or epileptic events may be missed. The correct interpretation of the aEEG patterns has a complex learning curve.

Method An e-learning course about monitoring the neonatal brain was developed to ensure that nurses are able to learn at any time, at any place on any computer. The hospital provided an e-learningteam. The e-learning course is located at a virtual learning environment which every member of the hospital staff has access to.

Results We developed an e-learning course which provides an interactive teaching tool to learn all about the near infra-red spectroscopy (NIRS) and four different aEEG monitor devices. Quizzes are included to practice how to interpret the aEEG recordings, which is essential in evaluating the monitoring of the neonatal brain.

Conclusion E-learning is an interactive learning tool which will enable the staff to keep their skills up to date in using different NIRS- and aEEG monitors and will allow correct interpretation of the aEEG recordings.

Acknowledgements Onbegrensd Leren (Learning without borders) UMC Utrecht.

\section{Nursing - Neonatal Pulmonology}

\section{PO-0869 DEVELOPMENT AND IMPLEMENTATION OF EVIDENCE BASED CLINICAL GUIDELINE REGARDING ENDOTRACHEAL SUCTIONING OF THE INTUBATED NEONATE}

${ }^{1} \mathrm{C}$ Riiser, ${ }^{2} \mathrm{RL}$ Stenkjær, ${ }^{3} \mathrm{~S}$ Nystrand. ${ }^{1}$ Neonatal Unit, University Hospital of Copenhagen, Dragør, Denmark; ${ }^{2}$ Neonatal Unit, University Hospital of Copenhagen, Kastrup, Denmark; ${ }^{3}$ Neonatal Unit, University Hospital of Copenhagen, Maaløv, Denmark

\subsection{6/archdischild-2014-307384.1493}

There is sparse evidence regarding endotracheal suctioning procedures in neonatal intensive care. We undertook a systematic literature review on following topics:

1. Suctioning frequencies

2. Pre-oxygenation

3. Installation of normal saline

4. Catheter size

5. Suctioning depth

6. Suctioning strength

7. In-line suctioning versus open suctioning

8. Recruitment manoeuvres

Results showed some evidence that suctioning could safely be performed as rarely as every eight hours plus as needed, that catheter size should not be larger than $70 \%$ of internal diameter of endotracheal tube size, that catheter only should be inserted as far as the tip of the tube, and that closed in-line suctioning systems could be used, and might be beneficial in neonates.

There is to sparse evidence regarding pre-oxygenation, installation af saline, strength of vacuum and recruitment manoeuvres to give evidence based recommendation.

The Neonatal unit in University Hospital of Copenhagen then changed suctioning guidelines accordingly to the recommendations found in the literature review.

We planned an implementation strategy inspired by Berwick and Bataldan's 'The Breakthrough Series', and Rogers 'Diffusion of Innovations', starting with baseline monitoring of chosen indicators such as incidence of occlusion of tubes, re-intubations, days on ventilator, length of stay, incidence of VAP, morbidity and mortality.

The implementation process was and is monitored by visual charts, graphs and numbers of the chosen indicators, and is a interdisciplinary focus in the unit.

\section{Nursing - Primary Care and General Paediatrics}

\section{PO-0870 THE SEXUAL DEVELOPMENT AND EDUCATION OF PRESCHOOL CHILDREN: KNOWLEDGE AND OPINIONS FROM DOCTORS AND NURSES}

${ }^{1} \mathrm{M}$ Kurtuncu, ${ }^{2} \mathrm{~L}$ Utas Akahn, ${ }^{3} \mathrm{I}$ Tanir, ${ }^{4} \mathrm{H}$ Yildiz. ${ }^{1}$ Pediatric Nursing, Bulent Ecevit University, Zonguldak, Turkey; ${ }^{2}$ Psychiatric Nursing, Bulent Ecevit University, Zonguldak, Turkey; ${ }^{3}$ Medical Doctor, Sultanbeyli State Hospital, Istanbul, Turkey; ${ }^{4}$ Nursing, Uludag University, Bursa, Turkey

\subsection{6/archdischild-2014-307384.1494}

Background and aims Especially the period between the ages of 0-6, which is known as the early childhood period (preschool period), is a very critical period where learning is fastest, the child is affected the most from environmental factors, and the 